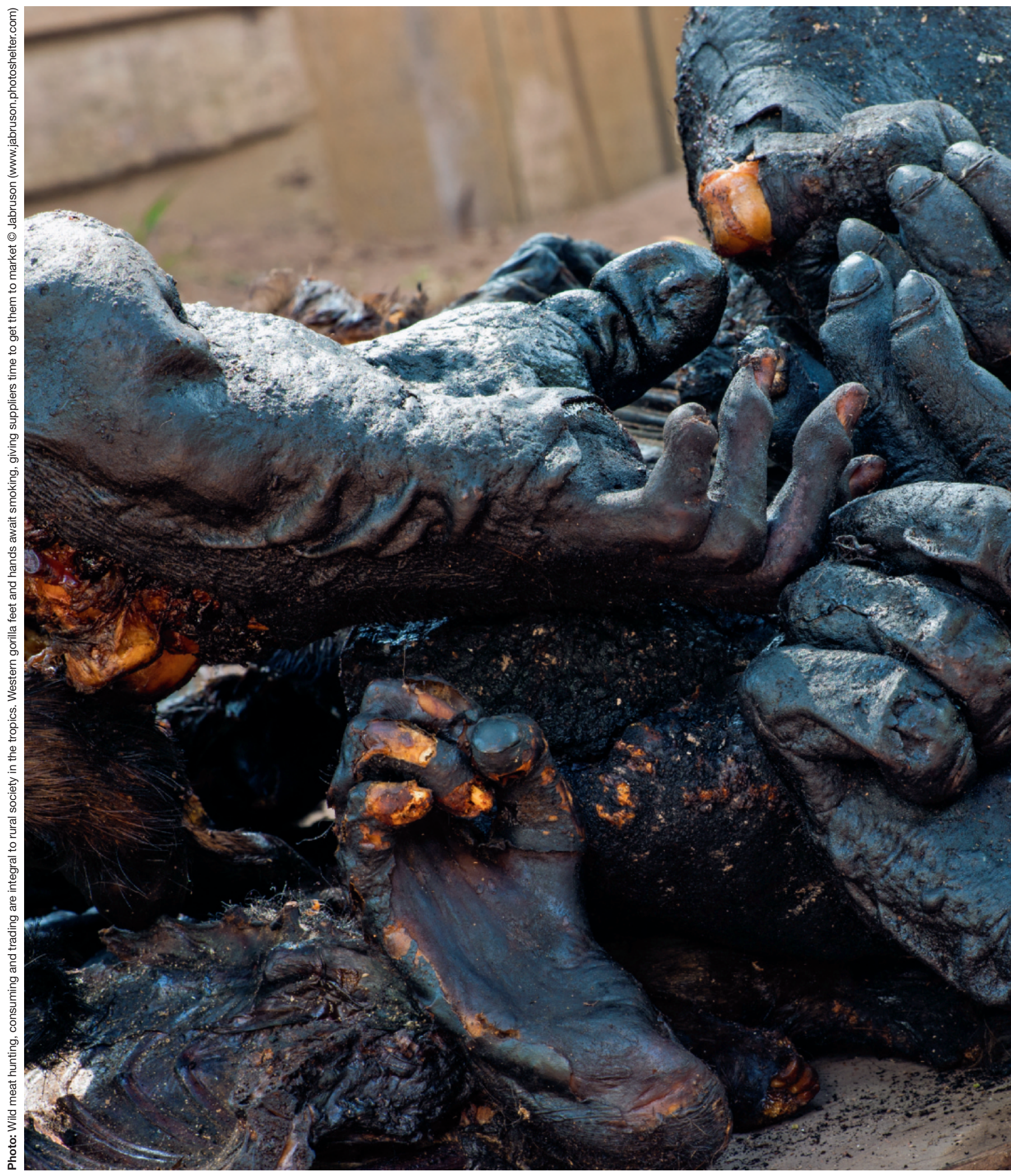




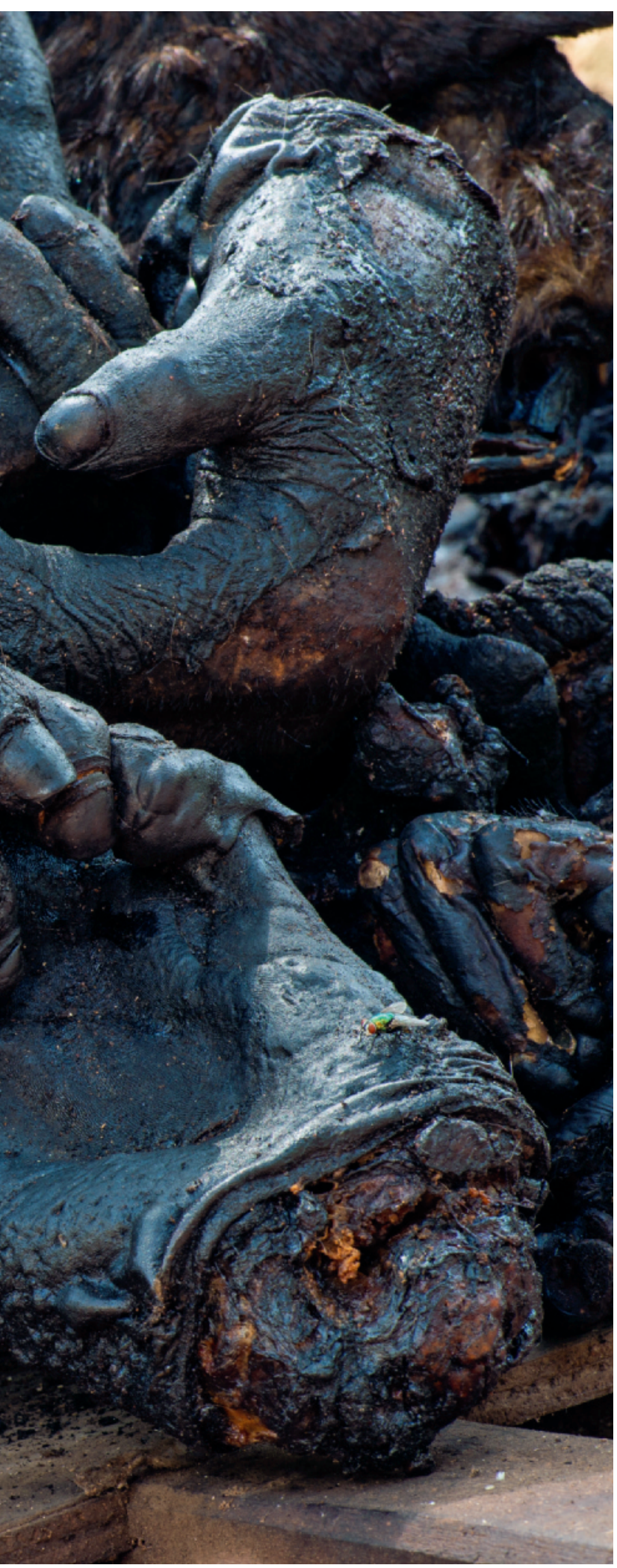

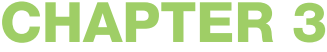

\section{Socioeconomics and the Trade in Ape Meat and Parts}

\section{Introduction}

The hunting of great apes and gibbons for their meat and parts is embedded in the overall practice of killing and capturing wild species, or wild meat hunting (Coad et al., 2019). In Southeast Asian forests, for instance, hunters target a large number of species for their meat, including gibbons (Harrison et al., 2016; Stokes, 2017). In considering the trade in ape meat and parts, this chapter focuses on great apes rather than gibbons, as far more information is available about the former than the latter. The chapter first outlines the scale of the problem and the general consequences of hunting great apes and primates in general. It then details the socioeconomic drivers of wild meat hunting and reviews the information available 
on great apes. In closing, it presents barriers to curbing the wild meat trade, as well as potential solutions.

People hunt wild animals for their meat in a large variety of ecological and cultural settings, ranging from savannah to rainforest biomes in the tropics and subtropics. While no information is available about great ape populations that lived in prehistoric times, evidence indicates that wild meat has long served as a source of protein and income for millions of people throughout the world. The emergence of lithic technology around 2.6 million years ago appears to signal increased hominid carnivory (Isaac, 1978). However, the details remain enigmatic due to sketchy zooarchaeological records and the difficulties inherent in distinguishing between scavenging and systematic hunting (Ferraro et al., 2013; Isaac, 1978).

Zooarchaeological assemblages of small bovids from about 2 million years ago, found at three sites in Kenya, possibly constitute the earliest indirect evidence of hominin hunting practices (Ferraro et al., 2013). The earliest direct evidence of systematic hunting by pre-modern hominins stems from wooden throwing spears that date back about 400,00o years; these items were discovered in Germany alongside stone tools and butchered remains of horses (Thieme, 1997). Evidence for ambush hunting of large animals comes from communities of Homo erectus in the Kenyan Rift Valley between about 1.2 million and 500,000 years ago (Kübler et al., 2015). The effects of hunting on wildlife abundance, distribution and extinction remain contested (Barnosky et al., 2004; Faith, 2014; Nagaoka, Rick and Wolverton, 2018).

Hunting by humans seems to have contributed to the extinction of some Pleistocene megafauna in a spatially heterogeneous manner. There is scant evidence, however, that hunting was a factor that led to the disappearance of any of the 24 large mammal species known to have become extinct in continental Africa in the late Pleistocene and early Holocene (Faith, 2014). Although it was once thought that "overkill" by early hunters caused the extinction of many species, evidence in the Americas remains ambiguous (Martin, 1958; Meltzer, 2015; Nagaoka, Rick and Wolverton, 2018). On the one hand, early people of the Americas exhibited a very broad spectrum of diets of which megafauna constituted only a small part (Dillehay et al., 2008, 2017). On the other hand, humans were implicated in the demise of megafauna from 37 genera, even though hunting evidence covers only five of the extinct taxa (mammoths, mastodons, gomphotheres, camels and horses) and the relative contribution of hunting versus other causes, such as climate change, is unresolved (Meltzer, 2015).

Orangutans were extinct in Southeast Asia and Java by the time of the Pleistoceneto-Holocene transition. Hunting is thought to have contributed to their demise, alongside other anthropogenic changes to the environment, while a low human population density might have saved orangutans from extinction in Borneo and Sumatra (Harrison, Krigbaum and Manser, 2006). In Madagascar, hunting severely impacted megafauna 2,000 to 1,00o years ago (Burney, Robinson and Burney, 2003).

There is mounting evidence that wild meat hunting was replaced by agropastoralism using zebu (Bos indicus) husbandry, which caused landscape changes associated with burning woodlands for pasture (Burns et al., 2016). Thus, both wild meat hunting and abandonment of hunting for agropastoralism have contributed to the extinction vortex at different points in time, highlighting the complex impacts of wild meat hunting on population dynamics (Crowley et al., 2017).

The effects of hunting and carnivory on human cultural and biological evolution 
Where species are not only targeted for their meat for local and regional consumption, but are also illegally traded internationally, the consequences can be particularly severe. Forest elephants (Loxodonta cyclotis), for example, are primarily poached for ivory, but their meat is an important by-product (Matschie, 1900; Stiles, 2011). In a period of only ten years (2002-11), the forest elephant population declined by about $62 \%$ and its geographic range decreased by around 30\% (Maisels et al., 2013). Poaching of elephants for their ivory is widely supported by interwoven local, regional, national and international networks. Such widespread demand for an animal part can lead to species extinctions and-not unlike in the drug trade-can cause a cascade of devastating social consequences (Brashares et al., 2014; van Uhm and Moreto, 2017).

Even where international trade has not been established, a health fad is enough to trigger either international or regional demand from an existing national network. Traditional Chinese medicine has become highly popular around the world and thus drives illegal trade in tiger body parts (Wong, 2015). In Cameroon and Nigeria, the skulls, bones, hearts and hair of the critically endangered Cross River gorilla (Gorilla gorilla diehli) are used in traditional medicine to treat a range of inflictions, from mental illness to rheumatism, impotence and bone fractures (Etiendem, Hens and Pereboom, 2011). For more information on cultural drivers of the ape trade, see Chapter 2.

Given the illegal nature of the trade in ape meat and parts, it is very difficult to obtain information and data on its scale and impacts. Subsistence hunters who provide food for use in the home, for instance, regularly sell their surplus, including protected species; similarly, opportunistic hunters in search of small game are likely to capture and kill protected species if the opportunity arises (Abernethy et al., 2013; Coad et al., 2019).
Hunters who supply the meat trade may find that selling body parts as by-products increases the profitability of wild meat hunting (Lindsey et al., 2012). The trade is complex, involving a number of different actors, from the poachers at the source, to any number of actors within the source nations (see Box 3.1), including those working internationally, such as crime groups and corrupt government officials, and through to a range of facilitators involved in demand countries (Lawson and Vines, 2014). While data on the hunting of apes remain limited, they indicate that the general dynamics of the wild meat trade also apply to primates.

Although many people who live close to nature consume animals ranging from elephants to gorillas to caterpillars, terrestrial vertebrates (amphibians, reptiles, birds and mammals) make up most of the biomass extracted and eaten in the tropics (Coad et al., 2019). Among vertebrates, mammals are the main source of wild meat in many regions of tropical Africa, South America and Asia (Robinson and Bennett, 2004). Three taxonomic groups account for more than three-quarters of the mammal species consumed across Africa, South America and Asia: primates (53\%); ungulates, or hoofed animals (16\%); and rodents (7\%) (Fa et al., 2013).

A comprehensive literature review indicates that wild meat hunting generally focuses on medium-sized animals but that larger species are taken opportunistically. These large species, including great apes, afford good returns simply because of the total volume of meat, thus encouraging hunters to grasp the opportunity when it arises, but not necessarily because of any particular preference for their meat. Although primates are among the taxonomic groups that are most hunted for their meat, monkeys and apes rarely account for more than $20 \%$ of the wild meat sold on African markets (Cawthorn and Hoffman, 2015; Robinson and Bennett, 2004). For most consumers 


\section{BOX 3.1}

\section{The Great Ape Commodity Chain in Cameroon}

The general route of wild meat from its source to its point of consumption is well understood. In simple terms, hunters provide game to middlemen, who supply market vendors, who openly display various types of wild meat and sell them to consumers (Cowlishaw, Mendelson and Rowcliffe, 2005; Robinson, Redford and Bennett, 1999). Since great apes are protected by law, the ape meat commodity chain remains clandestine and therefore difficult to monitor. Once a middleman receives an order and a monetary deposit from a buyer, he asks a hunter in a rural part of the country to dispatch the ape meat. Having received the meat, the middleman has it delivered to the buyer at a secret location. If authorities are complicit in the deal, the trafficker can operate more openly. Traffickers typically use the same logistics to transfer live animals and wild meat orders from hunters to buyers, since poachers who hunt great apes for their meat often sell live orphaned babies (Clough and May, 2018).

A study by Tagg et al. (2018) used questionnaires and interviews to investigate activities and motivations of actors involved in the ape meat trade in the northern and western periphery of the Dja Faunal Reserve, in southeastern Cameroon (see Figure 3.1). Participants included hunters, carriers and traders, as well as consumers, forestry administrators and middlemen, who facilitate the trade in different ways. Figure 3.2 illustrates the commodity chain in which these actors operate.

The hunters in this study comprised both opportunistic and specialized hunters, helped to varying extents by porters. Carriers included drivers of logging trucks, buses, taxis and private cars; some provided information about illicit means of traversing checkpoints, such as relying on the complicity of wildlife officials at checkpoints and the impunity of passengers and drivers of certain registered vehicles. Tradersincluding wholesalers and retailers - typically work in markets and restaurants, but they also sell from home; most of them partake in other activities, such as agriculture or bee farming. Traders can buy directly from hunters or from middlemen. Many middlemen are forestry officials who can be motivated to supply politicians and other members of the elite, and who consequently enjoy some level of impunity. Consumers, who can buy from hunters, middlemen or traders, are the final link in the chain. The part of the chain in which meat is being traded varies in length depending on the number of

\section{FIGURE 3.1}

\section{The Dja Faunal Reserve and Environs, Cameroon}

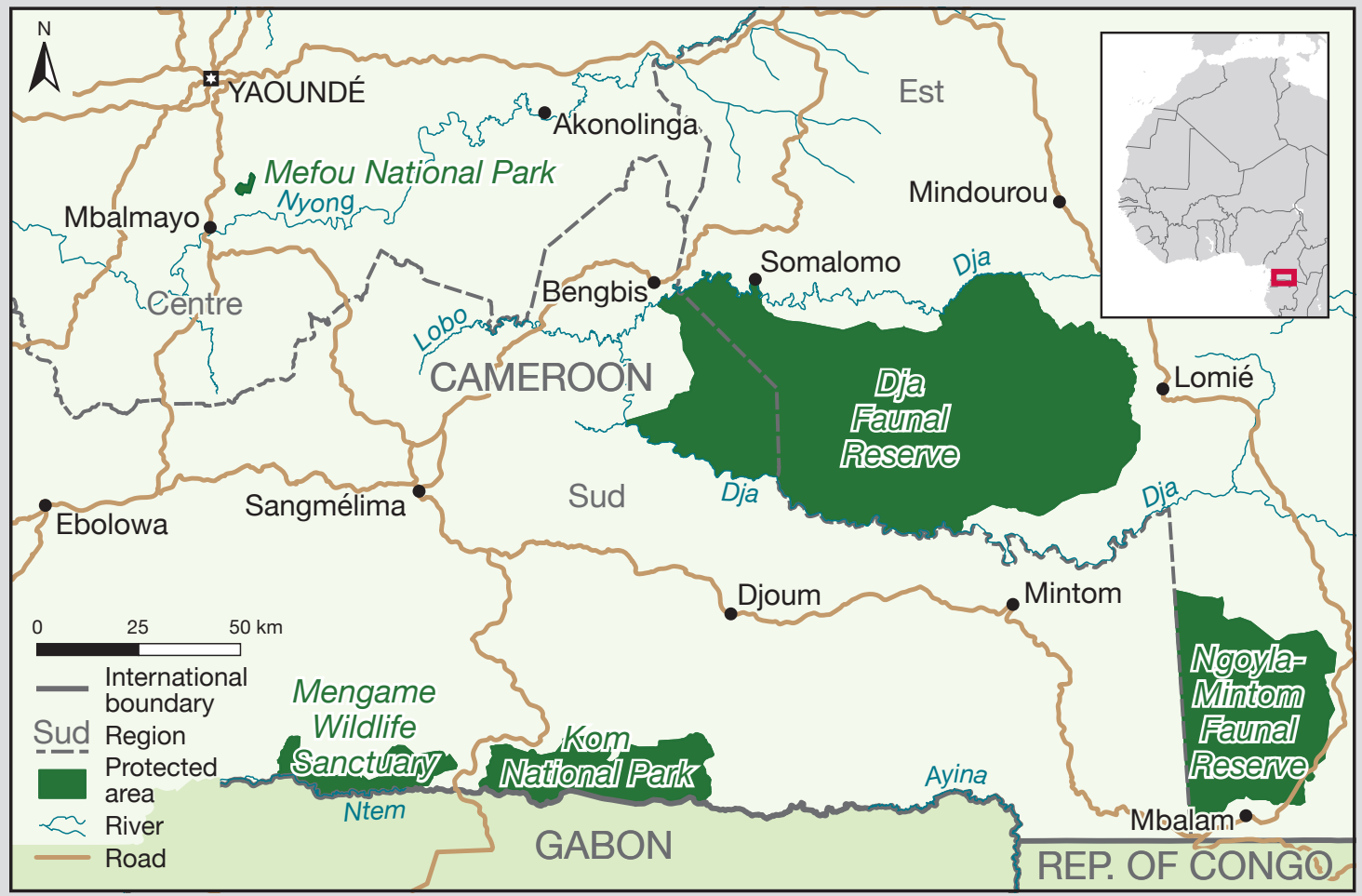

Source: UNEP-WCMC (2019b) 


\section{FIGURE 3.2}

\section{The Great Ape Meat Commodity Chain of the Dja Region, Cameroon}

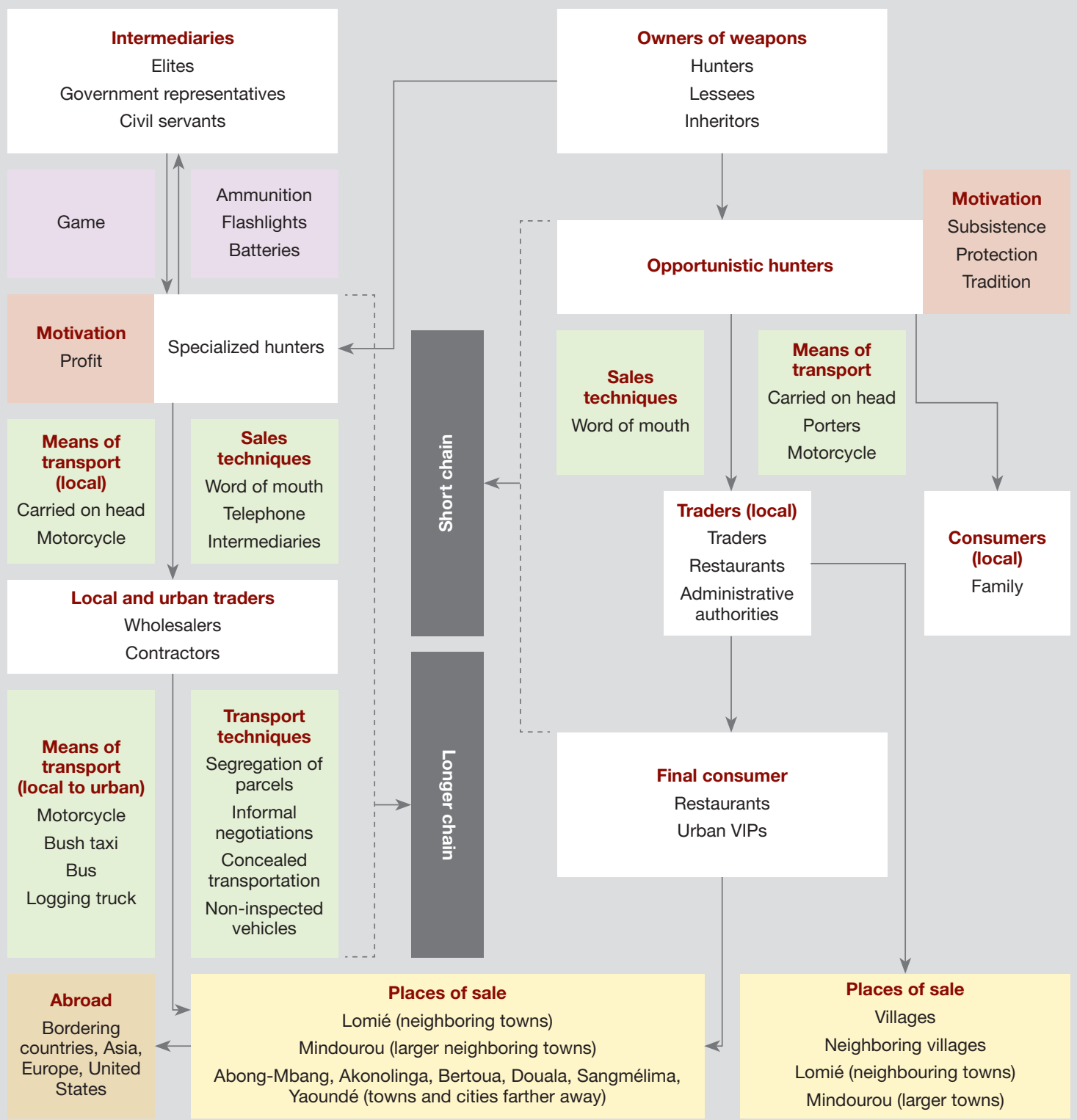

traders involved. If a trader sells meat to an individual who consumes it at home, then that consumer represents the end of the chain; if the first consumer is also a trader and sells the meat to someone else, the chain grows longer (Tagg et al., 2018).

The study results indicate that most ape meat consumption occurs close to home, although some shipments are sent to international recipients. The findings also show that middle- men reap the greatest returns, possibly because their input is very low and they enjoy some impunity. Specialized hunters earn high incomes, but they incur the risks of the hunt. Opportunistic hunters gain little because they sell quickly and at low cost to avoid being caught with illegal meat. Wholesalers have limited expenditures, but their profits are low; they prefer to buy more and spread costs across different species to minimize risk (Tagg et al., 2018). 
in urban areas, the origin of wild meat is rarely of importance as they tend to select the cheapest variety (Wilkie et al., 2005). The opportunistic aspect of the wild meat trade is also reflected in an inverse relationship between the volume of fish and the amounts of wild meat sold in rural markets in Ghana (Brashares et al., 2004).

\section{The Scale of the Problem for Great Apes}

High local, regional, national and international demand for live bonobos, chimpanzees, gorillas and orangutans-as well as their meat and body parts-leads to the killing of thousands of animals annually; however, information on market values and trade volumes remains sketchy. In the case of orangutans, adults tend to be killed, while their young enter the live animal trade. Killed orangutans are not supplied into the wild meat trade, as there is neither local nor international demand for their meat. In general, great ape meat forms part of traditional diets only in West and Central Africa, especially among non-Muslim populations (Clough and May, 2018). The wild meat and live animal trades are intertwined; meat is often obtained as a by-product when adults are killed to acquire young individuals, and vice versa.

While demand for meat and live animals is high, both locally and internationally, local subsistence hunters gain significantly less than the criminal networks and corrupt profiteers, as is also the case in the narcotics trade (van Uhm, 2018b; see the Introduction and Chapter 4). Notwithstanding this disparity in income, local commercial hunters in Africa can earn US\$300-1,000 annually, which exceeds the average annual household income and competes with the income of "those responsible for regulating the trade" (Okiwelu, Ewurum and Noutcha, 2009, p. 7).

\section{The Indonesian Market}

Limited information is available both on the role of hunting in food security among rural communities in Asian tropical forest environments and on the impact of wild meat hunting and trade in orangutans (K.L. Sánchez, personal communication, 2019). Domestic demand for orangutan meat is probably insignificant in Indonesia since the country is predominantly Muslim and eating primates is considered haram (forbidden). The Sumatran orangutan (Pongo abelii) is mainly targeted for the domestic live animal market rather than for the international trade, as Indonesia lacks the type of illicit supply network found in West and Central Africa (Clough and May, 2018). In Borneo's Kalimantan, however, an estimated 2,000-3,000 orangutans (Pongo pygmaeus) are killed annually for their meat, as incidental offtake associated with the live animal trade and in human-wildlife conflicts; that figure exceeds previous estimates and is likely to be unsustainable (Meijaard et al., 2011a). Small amounts of orangutan meat may be sold outside of Kalimantan's urban areas, not within them (Clough and May, 2018).

Hunting probably played an important role in the local extinction of some orangutan populations within their historical range (Marshall et al., 2006; Meijaard et al., 2011a, 2011b). The dramatic decrease in orangutan numbers in Borneo over the past 20 years has also been the result of changes in land cover, mainly because of habitat fragmentation and loss due to the conversion of forest to agricultural land, and associated deforestation (Voigt et al., 2018; Wich et al., 2008). This encroachment into orangutan habitat heightens the risk of conflict between humans and orangutans, such as retribution killing for economic loss caused by crop raiding (Marshall et al., 2006).

A useful indicator of orangutan killing is the number of baby or infant orangutans 
Photo: A useful indicator of orangutan killing is the number of baby or infant orangutans rescued, handed over or confiscated by the authorities and taken in by orangutan rescue centers. Rescued infants represent the deaths of their mothers - and possibly of more individuals. (C) Paul Hilton/ Earth Tree Images rescued, handed over or confiscated by the authorities and taken in by orangutan rescue centers across Borneo and Sumatra (Nijman, 2005). In 2000-04, three of Kalimantan's seven centers took in an average of 104 individuals per year; the average climbed to 107 for the period 2005-13 (Nijman, 2005; K.L. Sánchez, personal communication, 2019). Since rescued infants represent the deaths of their mothers-and possibly of more individuals - the high rate of orangutan offtake demonstrates that the mortality rate is also high (K.L. Sánchez, personal communication, 2019).

\section{African Markets}

In the Congo Basin, most towns and cities operate regular wild meat markets (Colyn, Dudu and Mbaelele, 1987; Fa et al., 2006; Juste et al., 1995). In Africa, this massive degree of wildlife extraction for meat and parts represents a severe threat to bonobos (Pan paniscus), chimpanzees (Pan troglodytes), Grauer's gorilla (Gorilla beringei graueri) and western lowland gorillas (Gorilla gorilla gorilla). Research indicates this trade constitutes a sizeable-yet generally underestimated-part of the economies of many

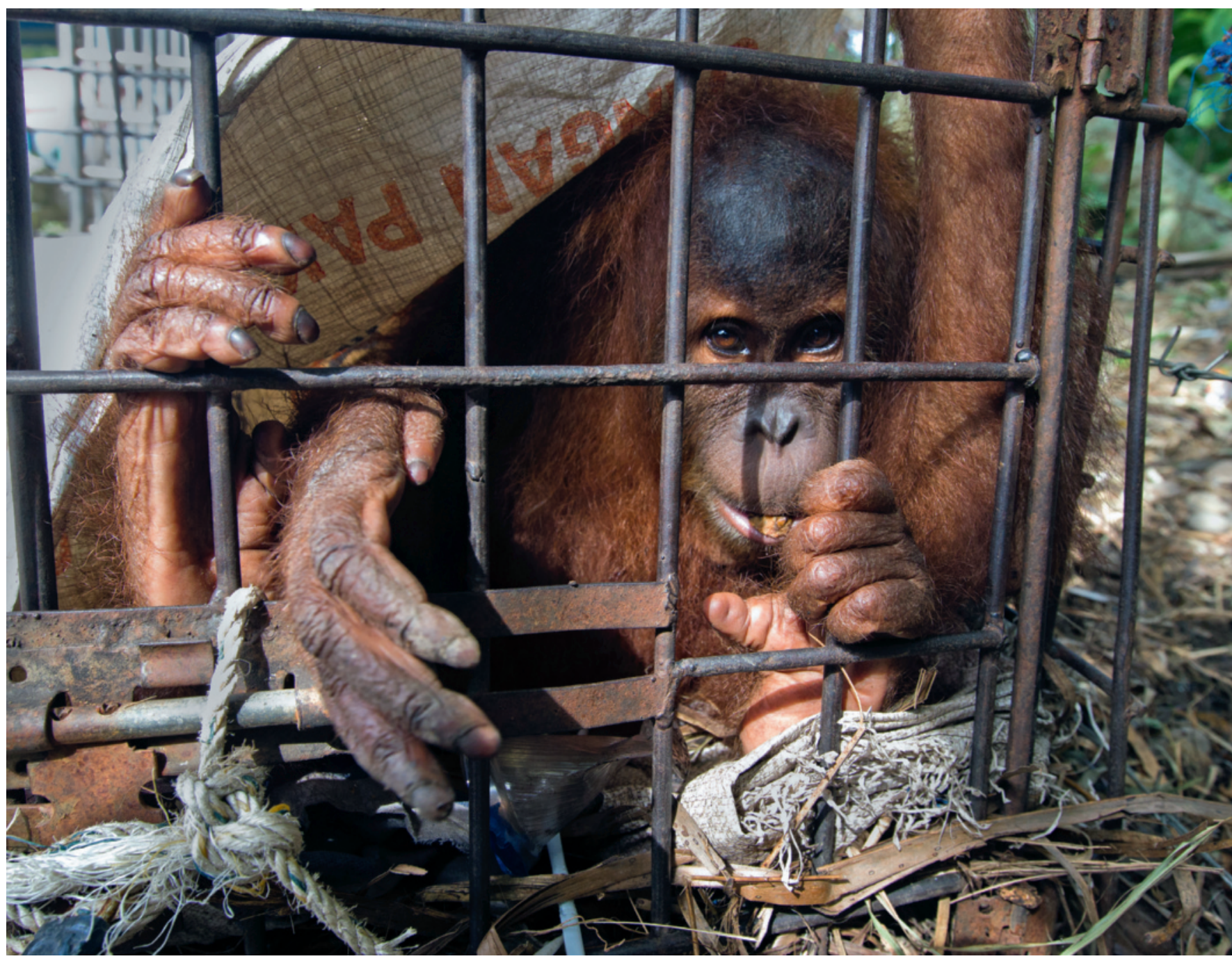


African countries (Lescuyer and Nasi, 2016). In the range states of the affected great ape species, the combined trade is valued at anywhere between US\$650,000 and US\$6 million per year, which accounts for a significant proportion of the overall wild meat market (Clough and May, 2018). This broad range reflects similarly wide variations in the price of meat: from about US $\$ 1.31$ to US $\$ 12$ per kilogram. Urban consumers in Central and West Africa typically pay the highest prices for great ape meat, suggesting that profit margins are high for suppliers, who probably collect most of the payments in cash (Clough and May, 2018). In many locations where great ape meat is consumed regularly, it is considered a choice commodity, for various reasons. In Lomié, Cameroon, for instance, people who eat gorilla meat tend to prefer the chest, hands and ribs because they are believed to impart respect, courage, strength and skill (Tagg et al., 2018).

In Cameroon's Dja Faunal landscape, costs depend in part on whether a hunter is specialized in great ape meat. While an average hunter can charge US $\$ 2-3$ for a piece of smoked chimpanzee and a bit more, US $\$ 3-6$, for gorilla meat, specialized poachers can earn US\$9-10 (Tagg et al., 2018). Similar price differences apply to whole apes. While a gorilla can generally fetch US\$6585 and a chimpanzee US $\$ 25-35$, specialized poachers ask for roughly double those prices: US $\$ 135-170$ and US $\$ 50-60$, respectively (Tagg et al., 2018). One study found that some poachers are able to sell whole chimpanzees for up to US $\$ 100$ (Stiles et al., 2013). A comparison with the prices of unprotected species that are commonly sold at the markets is instructive: a $10-\mathrm{kg}$ duiker costs around US\$13, a 6-kg monkey about US $\$ 6$ and a $3-\mathrm{kg}$ porcupine roughly US $\$ 4$ (Tagg et al., 2018).

Market surveys and reported consumption rates allow for estimates of the volume of wild meat extracted from some African forests (Fa, Peres and Meeuwig, 2002; Wilkie and Carpenter, 1999). About 4 million tons of wild meat are removed from the Congo Basin every year, yielding an extraction-toproduction ratio of 2.4-which indicates that 2.4 times more biomass is extracted from the wild than is produced (that is, added to affected populations, typically via reproduction) (Fa, Peres and Meeuwig, 2002; Fa and Tagg, 2016). To counteract extraction rates, Congo Basin mammals would have to double their reproductive potential every year, which is clearly unachievable (Fa and Tagg, 2016). Hunting records and market surveys indicate that across the Congo Basinwith large regional variability-rare and vulnerable species such as great apes and elephants usually represent only a small proportion (often less than 5\%) of the total number of animals hunted (Nasi, Taber and van Vliet, 2011). A study conducted in Ogooué, Gabon, reveals that primates made up just over $6 \%$ of 2,647 captures undertaken by 26 village subsistence hunters in a year (Coad, 2007). Other research, however, shows that primates account for up to $40 \%$ of harvested carcasses (Nasi, Taber and van Vliet, 2011).

Although wild meat constitutes only a small proportion of the meat consumed in large cities-typically less than $2 \%$ of the annual dietary protein requirement-the corresponding volume consumed per person is significant (Wilkie et al., 2016). A recent study carried out in the Kinshasa-Brazzaville metropolitan area, which is home to around 15 million inhabitants, suggests that the local rate of wild meat consumption is high, even though the number of establishments offering wild meat for sale is low in comparison to outlets that sell other domestic meat ( $\mathrm{Fa}$ et al., 2019). A quick calculation indicates that even if each person in Kinshasa and Brazzaville eats only $1-2 \mathrm{~kg}$ of wild meat per year, 15-30 million $\mathrm{kg}$ could be consumed annually (Fa et al., 2019; Wilkie and Carpenter, 
1999). To get a better sense of this volume, it may be helpful to visualize the proportion accounted for by guenon monkeys (Cercopithecus spp.), a preferred species group in these metropolitan areas. Between 8,400 and 22,500 whole guenon monkeys are sold annually in restaurants across the two cities, yet they account for less than $1 \%$ of the total volume of wild meat entering the two cities (Fa et al., 2019).

\section{Measuring Global Offtakes}

Between 2005 and 2011, more than 22,000 great apes were killed or captured in Africa and Asia to supply the wildlife trade. On average, hunters thus removed more than 3,00o individuals per year from the forests (Stiles et al., 2013). The impact on ape populations is likely to be significant, especially given the species' low population densities and relatively low reproductive rates.

These data on trade volumes and values can only be seen as indicative, and mostly as minimum estimates, since accurate numbers are difficult to obtain due to the illegal nature of activities under review. Information on hunting of terrestrial species remains limited, although efforts are under way to gather, assess and monitor changes in available data sets from different studies, as demonstrated by Taylor et al. (2015). While the accuracy of aggregate numbers remains contested-especially since the age of most of the data, collected over 30 years, makes up-to-date assessments difficult-proxy indicators can be used to estimate regional and global offtakes (Ingram et al., 2015). An example is the mean body mass indicator, which uses the mean body mass within each sample as a proxy of species composition; a drop from larger to smaller species may indicate that a habitat is experiencing defaunation. Another example is the offtake pressure indicator, which measures the offtake pressure exerted on terrestrial species, as represented by the overall trend in the number of individuals of each species killed and removed across sites and years (Dirzo et al., 2014; Ingram et al., 2015).

\section{Biological Consequences of Hunting for Meat and Parts}

\section{Wildlife Reductions and Losses}

A recent meta-analysis of 176 studies across the tropics shows that relative abundances in hunted areas compared to non-hunted areas were $83 \%$ lower for mammals and 58\% lower for birds (Benítez-López et al., 2017). A comparison of mammal species densities across 101 non-hunted and hunted sites in Amazonia points to significant population declines for 22 of the 30 considered species at high levels of hunting, with an 11-fold decrease in population biomass for the 12 hunting-sensitive species (Peres and Palacios, 2007). ${ }^{1}$

Long-term, detailed monitoring studies are surprisingly rare for primates in countries with prime habitat, mainly due to logistical constraints, a lack of rigor in data collection and data biases (Rovero et al., 2015). A pilot study on the Angolan blackand-white colobus (Colobus angolensis), the Sykes' monkey (Cercopithecus mitis ssp. albogularis) and the endangered endemic Udzungwa red colobus (Procolobus gordonorum) in Tanzania demonstrates that trained local technicians are efficient at implementing monitoring schemes (Rovero et al., 2015). Specifically, it reveals that all species inside a protected area remained stable over an 11-year period, but that two colobus populations outside the protected area suffered a marked decline, due to a combination of targeted subsistence hunting and habitat degradation (Rovero et al., 2012, 2015). 
In their stronghold of Kahuzi-Biega National Park in the Democratic Republic of Congo (DRC), Grauer's gorilla populations declined by $87 \%$ from 1994 to 2015 , mainly due to hunting, although the trend was exacerbated by civil conflict (Plumptre et al., 2016). Fifty-two percent of the total mountain gorilla (Gorilla beringei beringei) range lies within a $20-\mathrm{km}$ radius of camps for refugees and internally displaced people (Bender and Ziegler, 2009). Across the Congo Basin, western lowland gorilla and central chimpanzee (Pan troglodytes troglodytes) populations are significantly negatively correlated with hunting (Strindberg et al., 2018; Walsh et al., 2003). The spatial patterns and intensity of losses, however, are determined by the motivations of the hunters (Kühl et al., 2009).

In the northeastern Republic of Congo, nearly $7 \%$ of chimpanzees and $5 \%$ of gorillas may have been removed annually, from already low population densities of about 0.3 chimpanzees per $\mathrm{km}^{2}$ and 0.2 gorillas per $\mathrm{km}^{2}$. In contrast to other species that are pursued for their meat, great apes typically have low reproductive rates, which means that even low hunting pressure can lead to catastrophic population decline. Indeed, an annual offtake of $5-7 \%$ implies that the studied chimpanzee and gorilla populations were likely to be halved within 11-15 years-clearly an unsustainable rate (Kano and Asato, 1994). Even when hunting offtake diminishes
Photo: Grauer's gorilla populations, in their stronghold of Kahuzi-Biega National Park, DRC, declined by $87 \%$ from 1994 to 2015 , mainly due to hunting, although the trend was exacerbated by civil conflict. Grauer's gorilla at the Gorilla Rehabilitation and Conservation Education Center (GRACE), DRC. (C) GRACE

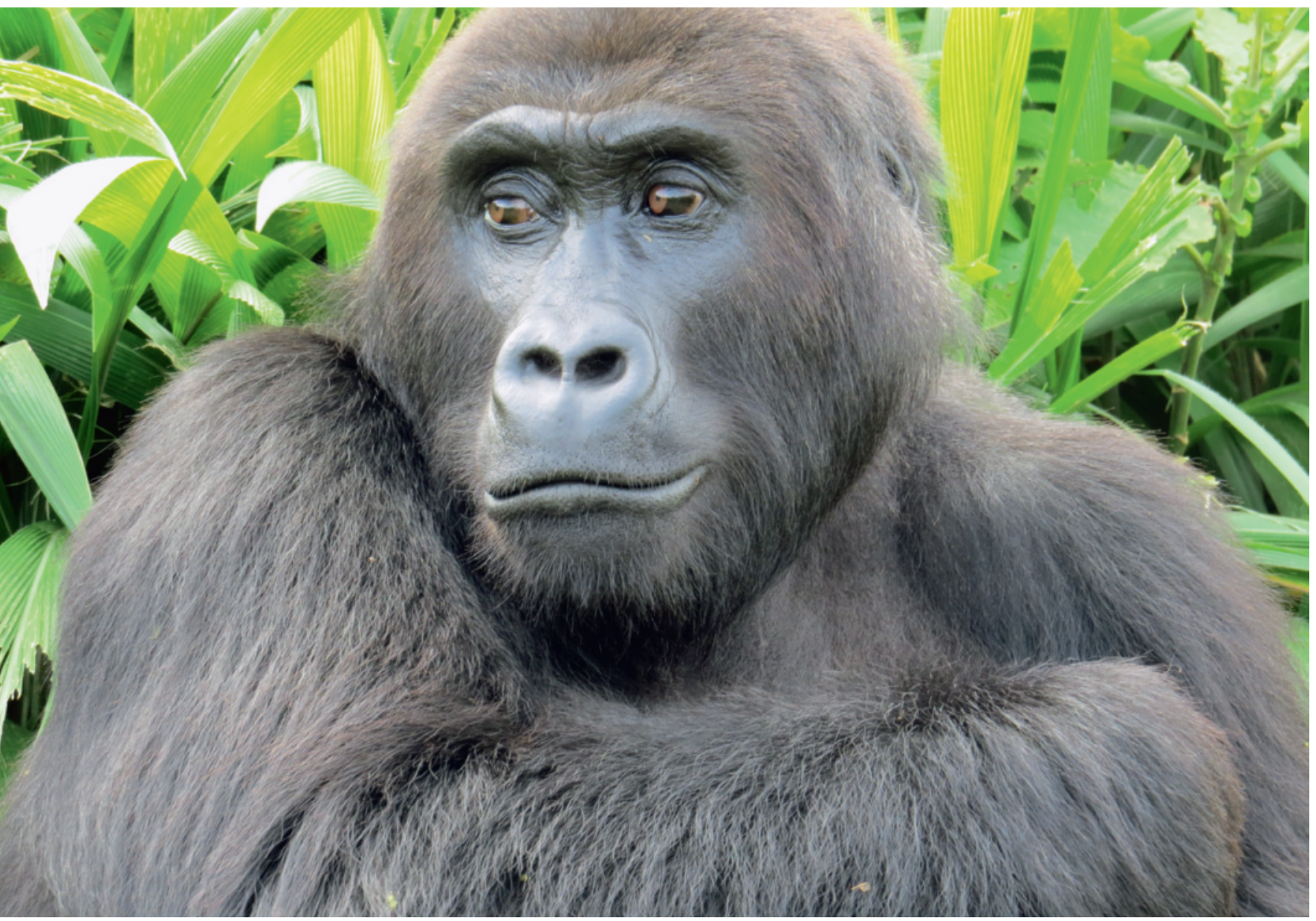


Great apes are

keystone species,

which play critical

functional roles, such

as seed dispersal.

Their loss reduces

the health of an eco-

system and ultimately

affects its provision

of life-giving, global

services, water and

carbon storage. with dwindling population density, it can maintain the local extinction vortex. Given their low population densities and low reproductive rates, great ape species cannot absorb such losses; instead, their survival in the wild is directly threatened. In this context, it is worth remembering that intensive hunting in fragmented forests appears to have driven Miss Waldron's red colobus (Piliocolobus badius waldroni) to extinction in Ghana and Ivory Coast (Oates et al., 2000, 2019).

Analyses conducted in 2002 suggest that African offtake levels, which are largely driven by urban demand for wild meat, were about $50 \%$ higher than production and at least four times higher than sustainable rates (Fa, Peres and Meeuwig, 2002). Barring changes in extraction rates, Central Africa's wild meat supplies are expected to decline significantly between 2003 and 2050, with drops ranging from $61 \%$ in the Central African Republic (CAR) to $78 \%$ in the DRC (Fa, Currie and Meeuwig, 2003).

There is sufficient evidence that unsustainable hunting leads to the local decline and extirpation of wildlife populations, as well as population isolation and the resulting loss of genetic and cultural diversity. Since small populations, such as mountain gorillas, inevitably inbreed, they suffer an accumulation of deleterious mutations and a decline in the fitness of the population (Xue et al., 2015). Distinct ape populations are known to exhibit a wide range of different cultural traits, many of which are being lost with local extirpations (Kühl et al., 2019). Furthermore, large-bodied frugivorous primates are keystone species, which play critical functional roles, such as seed dispersal (Lambert, 2011; Nuñez-Iturri, Olsson and Howe, 2008). The loss of these kinds of ecological engineers reduces the health of an ecosystem and ultimately affects its provision of life-giving, global services, water and carbon storage (Dirzo et al., 2014).

\section{Risk to and through Food Security}

Humans-including rural and forest people, who rely on wild meat as their only source of animal protein, and urban dwellers, who consume wild meat as a luxury (see below) drive unsustainable hunting throughout the tropics. Wildlife often plays an important role in rural communities, be it as a source of food, income and medicine; a target of hunting for crop protection; or as a feature of cultural traditions (Alves and van Vliet, 2018; El Bizri et al., 2015; Ichikawa, Hattori and Yasuoka, 2016; Nasi et al., 2008). A loss of wildlife thus results not only in the waning of a wide range of direct ecosystem services on which rural people rely, but also in the deterioration of their cultural identity. Given the scale of the current wild meat harvest and the persistent increase in human populations, it is almost inevitable that wildlife declines will continue, in turn threatening the very availability of wild meat (Ceballos, Ehrlich and Dirzo, 2017; Swamy and PinedoVasquez, 2014; Wilkie et al., 2011). The direct food security costs of faunal loss are expected to fall disproportionately on the millions of rural inhabitants across the tropics and subtropics-those who are the most dependent on wild meat and who have very few affordable alternatives at their disposal (MilnerGulland and Bennett, 2003).

In Cameroon and the DRC, a high proportion of the daily protein requirement is supplied by wild meat ( $\mathrm{Fa}$, Currie and Meeuwig, 2003). Data from the Poverty Environment Network, representing smallholder-dominated tropical and sub-tropical landscapes across 24 developing countries, demonstrate the importance of wild foods to food security: wild animal products are collected by about $21 \%$ of households, while only about $4 \%$ of households in forested areas and $2 \%$ in non-forested areas generate cash income from the collection (Hickey et al., 
2016). The data also indicate that poorer households derive a higher proportion of their income from hunting; that $39 \%$ of households engage in hunting activities, more than previously assumed; that the vast majority $(87 \%)$ of wild meat is consumed in hunting households; and that hunting contributes only $2 \%$ of cash income (Nielsen et al., 2017).

Wild meat contributes both macronutrients and micronutrients to a diet. A rare study quantifying the importance of wild meat for micronutrient acquisition shows that $14.3 \%$ of households that consumed wild meat in the Amazon acquired significantly higher levels of iron, zinc and vitamin $\mathrm{C}$ than other households. Moreover, wild meatconsuming households presented a higher nutritional status, with a lower intake of carbohydrates $(-10 \%)$ and a higher intake of proteins $(+46 \%)$,iron $(+151 \%)$ and zinc $(+23 \%)$ compared to the others (Sarti et al., 2015).

On the one hand, over-exploitation of wild meat destroys food security via local extinctions-a typical "tragedy of the commons" problem, as discussed below (Hardin, 1968). On the other hand, shifting food security into modern agriculture might also destroy biodiversity, affecting the same species that were previously hunted for wild meat. The rate of wild meat hunting and the importance of wild meat as a protein source are both inversely related to the consumption of alternative protein sources, such as fish or domestic livestock; as discussed below, the promotion of alternative meat sources is thus being hailed as one of the main strategies to limit the consumption of wild meat (Brashares et al., 2004; Nielsen et al., 2018). It needs to be stressed, however, that such studies use the term "domestic livestock" to refer to currently practiced subsistence husbandry, not to industrial,commercial agriculture (Nielsen et al., 2018). This research does not address the food security of urban dwellers, who- in contrast to rural consumers-often have access to other, affordable nutritious meats and are therefore less likely to suffer nutritional hardship if they are deprived of wild meat (Bennett, 2002).

If the urban demand for wild meat is successfully curtailed, the agricultural sector will have to undergo significant changes to produce food for Africa's ever-expandingand increasingly affluent-populations in cities and towns. The continent's urbanization trend is extraordinary: urban population density is expected to triple within the next 40 years and, by 2030, Africa will be home to as many as 9 megacities - with populations exceeding 10 million inhabitants (Güneralp et al., 2017; UN DESA, 2018). Promoting the expansion and productivity of the agricultural sector to meet the demands of more urbanized populations will have devastating consequences on natural areas, even if the growth rate of Africa's agricultural sector over the past 30 years $(+160 \%)$ is slower than Asia’s (+212\%) and South America’s (+174\%) (NEPAD, 2013).

Greater wealth in developing countries typically translates into increased meat consumption, as evidenced by the upsurge in China's annual per capita consumption of meat (which rose from $16 \mathrm{~kg}$ to $43 \mathrm{~kg}$ ) and milk (which rose from $3 \mathrm{~kg}$ to $8 \mathrm{~kg}$ ) between 1983 and 1997 (Delgado, 2003). Assuring food security outside the wild meat system is thus likely to exacerbate the loss of biodiversity and ecosystem services, which is fueled by land use changes that are designed to maximize agricultural yields for the more affluent local and global populations (Marques et al., 2019). A case in point involves land use change driven by the palm oil industry, which on the one hand provides local economic development, yet on the other causes the demise of the orangutan due to habitat change and increased humanwildlife conflict (Ancrenaz et al., 2015, 2016; Meijaard et al., 2011a). 
In Central Africa, only Cameroon, CAR and Gabon could prospectively maintain their population's protein supply above the recommended daily requirements $(46 \mathrm{~g}$ for women and $56 \mathrm{~g}$ for men). Maintaining current reliance on wild meat in the region not only implies that a substantial number of faunal species will become at least locally extinct relatively rapidly, but also that malnutrition will increase significantly in Central Africa unless food insecurity is promptly resolved by other means (Wicander and Coad, 2018; Wilkie et al., 2016).

In some circumstances, assuring food security entails replacing wild meat and fish with industrial chicken or canned meats, which are of less nutritional value (Dounias and Froment, 2011; Nardoto et al., 2011; Sarti et al., 2015; van Vliet et al., 2015). Overall, however, establishing food security outside the wild meat market will require an increase in locally available alternative meat and protein resources for optimal nutrition and, at the same time, a drawdown of ecologically inefficient and destructive systems, such as the farming of ruminants, as discussed below (Machovina, Feeley and Ripple, 2015; Oben, Molua and Oben, 2015).

\section{Drivers of Wild Meat Hunting}

\section{Socioeconomic Factors}

Poor societies tend to be more reliant on wild meat for survival and have fewer opportunities for developing alternative livelihoods. As poor people and hunters are more willing to participate in the illegal wild meat trade, many studies argue that profit is the main economic driver of wildlife crime (Duffy and St John, 2013; Duffy et al., 2016; Harrison et al., 2015; Leberatto, 2016). Sites where elephant poaching is rife, for example, have been described as suffering from relatively high levels of poverty, and people arrested for unauthorized hunting in Bwindi Impenetrable National Park in Uganda have been characterized as relatively poor (CITES, IUCN and TRAFFIC, 2013; Twinamatsiko et al., 2014).

The links between poaching and poverty are not fully understood, however. Both economic and geographic drivers have been associated with wild meat consumption, as the poorest communities consume most of the wild meat in rural areas and the wealthiest eat the greatest proportion in urban areas (Brashares et al., 2011). The interaction of drivers varies from one area to another, highlighting the need for interventions to be site-specific (Lindsey et al., 2012). In Borneo, for example, the rate at which orangutans are hunted and killed in any area is affected by local factors such as the degree of forest cover, the proportion of land used for agriculture, income levels, religion and the rate of habitat loss (Meijaard et al., 2011a; Santika et al., 2017). Consideration of a site's broader context is key to an effective, socially and environmentally just approach to tackling wildlife crime (Duffy et al., 2016).

As Amartya Sen points out, poverty denies people agency and the ability to lead fulfilling and meaningful lives. A hunter's decision to poach and trade in protected wildlife may thus also reflect an effort to affirm "identity, status, lifeways, custom, and local prestige" and "to define one's future and day-to-day activities" (Duffy et al., 2016, p. 16; Sen, 1999). This behavior suggests there is a need to develop ways to measure human well-being while also addressing the requirements of voice, prestige and status (Milner-Gulland et al., 2014; Sen, 1999). In this context, agency relates to individual choices and actions within a wider social context (Duffy et al., 2016). The role of agency is commonly observed in people's responses to community initiatives, which 
consumption provides substantial economic value and food security to many rural households (Reuter et al., 2016).

In times of economic hardship in rural communities, wild meat can serve as a "safety net contributing to livelihood security” (Schulte-Herbrüggen et al., 2013, p. 10). This idea has been proposed as an "inferior good hypothesis," according to which the poor rely on wild meat as a cheap, lowquality resource (Brashares et al., 2011). The hypothesis is supported by meta-analyses, such as Nielsen et al. (2017), which reveal wild meat to be increasingly replaced by domestic and purchased meats as household income increases. An understanding of this hypothesis can allow for the development of effective conservation interventions, which could potentially help to avert destabilizing effects of wild meat shortages and restrictions, such as positive feedback loops that lead to increased poverty, or "poverty traps" (Sachs, 2006). Ideally, such interventions could simultaneously contribute to poverty alleviation and to the protection of biodiversity (Nielsen et al., 2017).

Illegal commercial hunting, in contrast, is driven by factors such as weak law enforcement, easy access to markets (particularly for wild meat and ivory) and a lack of awareness of the law and consequences of wildlife crime (Harrison et al., 2015). An increase in illegal wildlife trade can be directly related to a rise in income, suggesting that the economic drivers of commercial wildlife crime may comprise a desire for wealth, on top of meeting basic needs (Duffy and St John, 2013; Harrison et al., 2015; TRAFFIC, 2008). Individuals who are exposed to consumer demand for wild meat, ivory or timber can experience a "pull factor" that may encourage them to become involved in wildlife crime; they may also succumb to "push factors," such as a lack of legitimate income sources, particularly around protected areas (Harrison et al., 2015).
In other words, while poverty may encourage people to poach for commercial reasons, individuals from poor communities do so in response to demand from wealthier communities (Duffy and St John, 2013). One example is elephant poaching, which has been linked to poverty, greed, poor law enforcement and weak governance, although the recent escalation in illegal killing is correlated with a growing demand for ivory as a luxury item in Asian countries (CITES, IUCN and TRAFFIC, 2013; Wittemyer et al., 2014). Similarly, in the DRC, hunting for the commercial wild meat trade is the primary threat facing primates (Estrada et al., 2018). The commercial value of chimpanzees, for example, is high because they are large animals whose parts can be traded for a variety of purposes. People consume their meat, and their skin can be used for decoration, their bones for professed therapeutic qualities and their skulls in connection with traditional rituals (Downing, 2012; Prescott, Rapley and Joseph, 1993-1994).

The demand for wild meat in cities encourages more hunters to engage in commercial operations in villages (Brashares et al., 2011; Coad et al., 2010; Fa and Tagg, 2016; Kümpel et al., 2010; Robinson, Redford and Bennett, 1999; Wilkie et al., 2005). City residents consume wild meat as a luxury item, often based on personal preference (Reuter et al., 2016). Since alternative meats are also more available in towns and cities than they are in rural areas, wild meat is not essential to the food security of urban consumers (Wilkie et al., 2016). This finding is supported by evidence that wild meat consumption is correlated to consumer wealth (Brashares et al., 2011; Fa et al., 2009). Restricting access to wild meat in urban centers-by curtailing the supply from rural areas-would thus contribute to biodiversity protection without directly affecting the food security of the poor ( $\mathrm{Fa}$ et al., 2019). 
Other socioeconomic forces may also be at play. The local literacy rate, as a measure of education level, is also reflected in poaching levels (de Boer et al., 2013). Educated people are more likely to be involved in legal cash income activities and therefore depend less on local wildlife resources for food (Junker et al., 2015).

\section{International Trade, Data Limitations and the Wealth Effect}

There is an international element to the wild meat trade, and the great ape trade in particular, with demand coming from Europe, the United States, the Middle East and Asia; however, consumption in these regions is likely to be limited compared to that of local residents in ape range states (see Box 3.2). In international markets, wild meat is always a costlier item relative to other sources of animal protein; as a result, it is considered a luxury item, served during holidays, to impress important guests or hosts, or simply to display wealth. Swiss customers, for example, pay around ten times more for great ape meat than consumers in Cameroon (Clough and May, 2018).

Since authorities rarely identify confiscated imported meat, it is not possible to determine the precise proportion of ape meat entering overseas markets as a proportion of all wild meat. About 40 tons of wild meat arrive at Geneva and Zurich airports every year, and more than 270 tons land at Charles de Gaulle in Paris, yet it is unclear how much of this volume is ape meat (Chaber et al., 2010; Clough and May, 2018). Great ape body parts are also in demand around the world; chimpanzee and gorilla parts, for instance, are sold in China, Nigeria and the United States. A lack of data precludes a detailed assessment of annual trade volumes, however (Clough and May, 2018).

\section{$30 \times 3.2$}

\section{Wild Meat Exports from Africa: The Role of Air Travel}

Recent reports about the popularity of pangolins and other endangered species may give the impression that international trade is generally driving unsustainable hunting in source countries. Research indicates, however, that of the total amount of wild meat extracted from tropical regions, only a small proportion is exported (Ingram et al., 2018).

Nevertheless, the international trade in wild meat is sizeable. While accurate trade figures remain elusive, studies show that wild meat is regularly exported to Washington, DC, as well as to capitals of European countries that are home to expatriate populations from former African colonies, such as Brussels, London, Madrid and Paris (Brown, Fa and Gordon, 2007; Harris and Karamehmedovic, 2009). A systematic analysis of the scale and nature of wild meat shipped from Africa to Europe via Paris found that more than five tons are smuggled through Charles de Gaulle Airport in personal baggage on a weekly basis (see Figure 3.3). Wild meat is imported not only for personal consumption, but also as part of a lucrative organized trade in luxury goods. The meat comes from a wide range of species, many of which are listed under the Convention on International Trade in Endangered Species of Wild Fauna and Flora (CITES) (Chaber et al., 2010).

A number of measures can help to curb the importation of wild meat into non-habitat countries. General steps include:

- strengthening border controls and intelligence to detect criminal hubs;

- improving meat detection at airports, such as through the use of dogs;

- training customs officers to distinguish key wild meat taxa;

- enhancing checks at ports of departure;

- appropriately fining those responsible for importing wild meat (Chaber et al., 2010; see Chapter 6).

Airline companies themselves can assist by:

- informing airline passengers that:

carrying wild meat in their luggage is illegal, as some airline companies already do;

- engaging in the illegal wildlife trade can lead to prosecution and substantial penalties; and

- the unsustainable extraction of wild meat has a detrimental effect on many endangered species;

inposing travel-related penalties on passengers who carry wild meat; and

dismissing airline staff members who participate in or allow the carrying of wild meat (Chaber et al., 2010). 


\section{FIGURE 3.3}

Direct Flights to Paris, from Airports in Proximity to African Ape Ranges

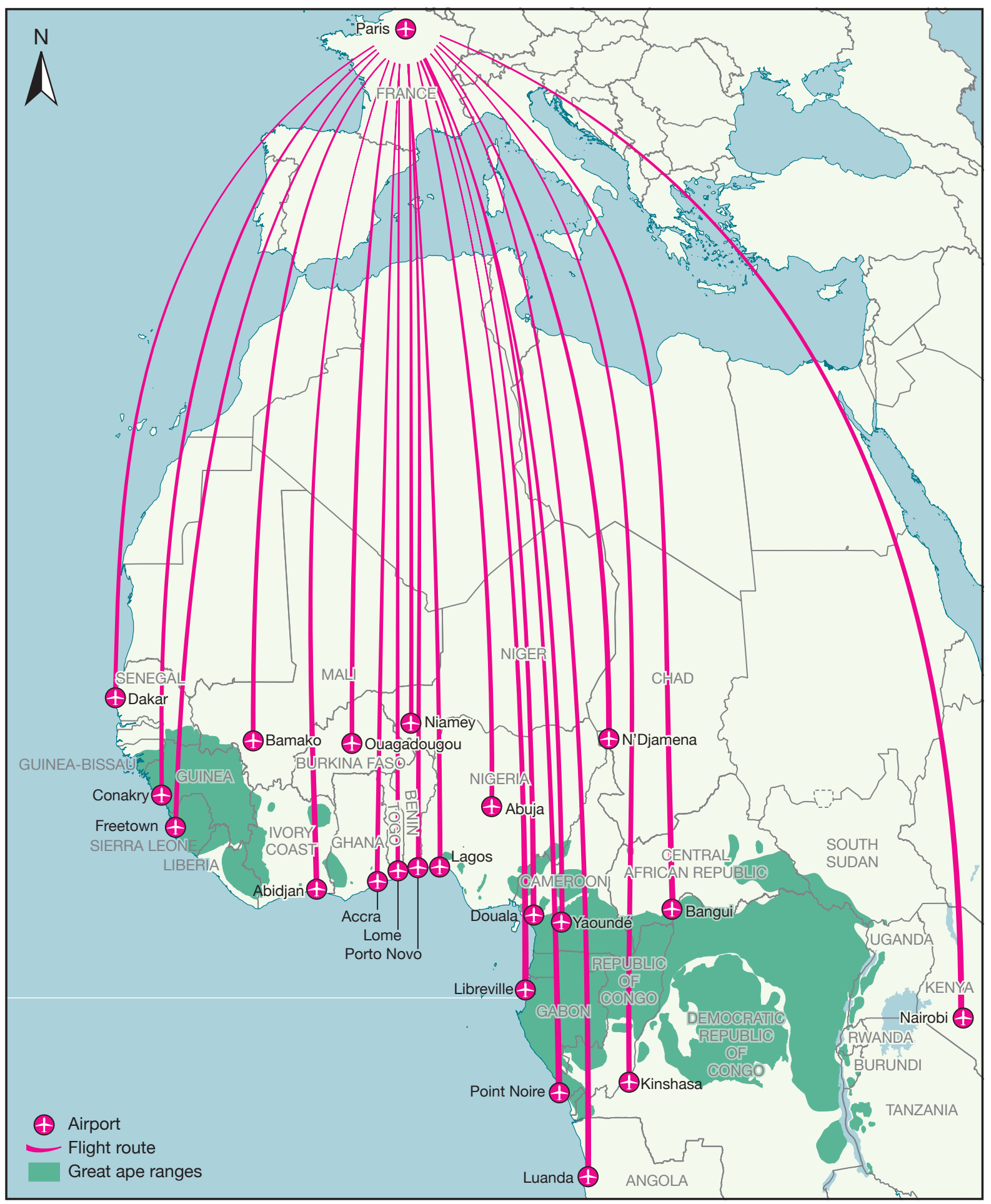

Source: Flightradar24 (n.d.) 
In addition to population growth, major drivers of national and international demand for wild meat include socioeconomic changes arising from increased wealth; as noted above, such trends are exemplified by the dramatic upswing in meat consumption in China over the past few decades (Delgado, 2003). Most developing countries are expected to experience similar surges imminently; and as their greenhouse gas emissions, water consumption and land use increase, they will experience a perfect storm of highly adverse environmental effects (Henchion et al., 2017).

\section{Governance, Law Enforcement and Corruption}

Weak governance facilitates wildlife crime. There are multiple, interrelated reasons why this is the case; for example, fines for poachers are often small, repeat offenses are rarely taken into consideration and neighboring countries often do not enforce the same laws or punishments (Lindsey et al., 2012; Rodriguez et al., 2018; see Chapter 6). Furthermore, the enforcement of laws is commonly encumbered: laws may not be adhered to voluntarily and officials often lack the resources to enforce them. For example, budget shortages and high security costs prevent authorities from employing sufficient anti-poaching patrols to deter wildlife crime in national parks (Lindsey et al., 2012; Rodriguez et al., 2018). Corruption within the system is a further detriment to this process. Officials can succumb to bribery and authorities may be hesitant to arrest those with links to government. Examples abound; in Central Africa, for instance, government officials have been implicated in the poaching of elephants and the ivory trade (Lindsey et al., 2012; Lindsey and Bento, 2012).

\section{Culture, Conflict and Technology}

Among traditional communities, cultural or religious practices may drive huntingor discourage it, for example through restraints on the consumption of certain types of meat (Junker et al., 2015; see Chapter 2). Muslim communities in Borneo tend not to hunt orangutans for meat consumption (Santika et al., 2017). Even in areas where there are local religious or cultural taboos against consuming ape meat, however, hunting can still threaten animals. In Guinea-Bissau, for instance, chimpanzee body parts are a common sight in rural and urban markets because they are used in traditional medicine to remedy disease, impotence and female infertility-despite widespread taboos against consuming chimpanzees (Sá et al., 2012).

In areas that are affected by conflict and the concomitant disruption of services, conservation efforts are impossible, and poaching levels tend to be unsustainably high. The national parks in Mozambique and the Garamba National Park in the DRC witnessed the decimation of wildlife populations as a result of armed conflict (de Merode et al., 2007; Hatton, Couto and Oglethorpe, 2001).

Wildlife can also suffer as a result of political uncertainty, such as land reform and the associated breakdown of law enforcement in Zimbabwe (Lindsey et al., 2011). In northwestern Tanzania, illegal hunting surged after refugee camps were sited close to wildlife areas (Jambiya, Milledge and Mtango, 2007).

Modern hunting tools and technology - such as rifles and traps, night vision and thermal devices, and helicopters-have also played an important role in increasing offtake, sometimes dramatically (Coad et al., 2019). 
Photo: Modern hunting tools and technologysuch as guns, traps, night vision, thermal devices and helicopters - have played an important role in increasing wildlife offtake. Anti-poaching patrol with gun cartridge case in the foreground, evidence of gorilla poaching, Plateau Bateke National Park, Gabon. (C) Cyril Ruoso/ naturepl.com

\section{Drivers of Hunting of Great Apes}

Most hunted great apes in the tropics are eaten, either close to the source, in urban areas of that country or internationally. Large-bodied mammals, including great apes, are the main source of wild meat in many tropical regions (Robinson and Bennett, 2004). Primates typically live in large groups, which renders them vulnerable and leads hunters to target them ( $\mathrm{Fa}$ and Tagg, 2016). While poachers generally rely exclusively on firearms to hunt arboreal apes (orangutans and gibbons) in Asia, Africa's terrestrial apes-bonobos, chimpanzees and gorillas-are not only at risk of being shot, but also susceptible to being caught in indiscriminate snares (Fa, Ryan and Bell, 2005).

Apes are essentially hunted for their meat, but they are also pursued for their parts. Traditional doctors in Cameroon, Guinea and Senegal use ape heads, hands and feet, and in the DRC consuming bon- obo fingers and toes is thought to pass on magical powers (Clough and May, 2018). Similarly, due to a belief that consuming gorilla parts passes on their strength to the recipient, some partake in a practice of burning and grinding gorilla bones to make a traditional "vaccine" (Clough and May, 2018; for more on cultural drivers, see Chapter 2). Great ape parts are also used in non-medicinal ways. For example, gorilla hair is thought to boost the production of fruit and pistachio trees (Tagg et al., 2018). Of note is an increasing interest in great ape skulls: the Last Great Ape Organization estimates that 900 ape skulls were trafficked in Africa in 2015 (Clough and May, 2018). Great ape skulls can be used as talismans; for example, chimpanzee skulls have been positioned in rivers to trigger rain (Tagg et al., 2018). Although orangutan skulls have been used as an ornament for costumes and dresses in modern celebrations, there is no strong evidence that orangutan body parts are regularly employed for traditional

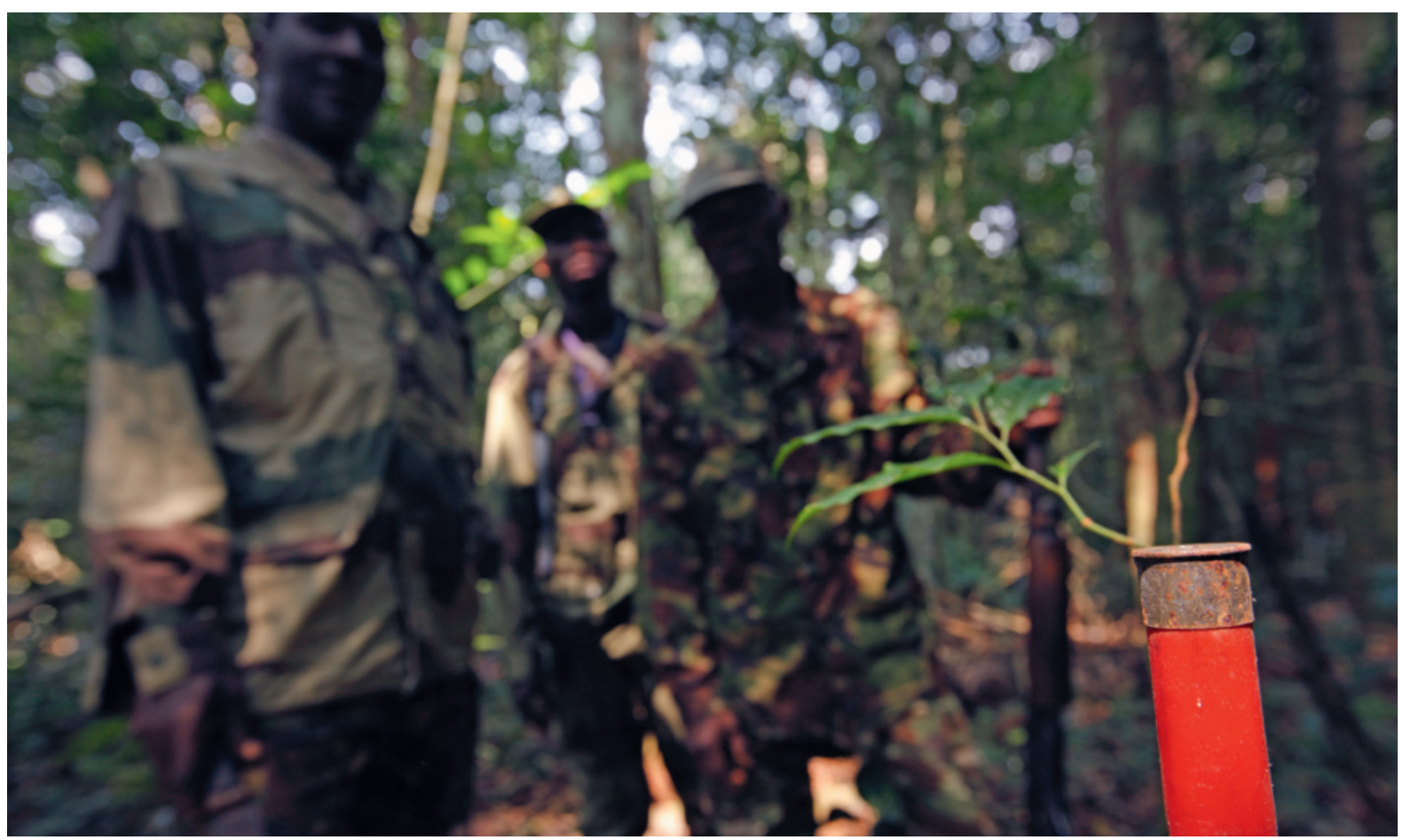


medicines, ceremonies or rituals (Clough and May, 2018; see Case Study 2.2).

Great apes may be hunted for other reasons. Studies show that orangutans in Indonesia have been killed out of fear, in self-defense, or to prevent-or retaliate forcrop-raiding (Davis et al., 2013; Meijaard et al., 2011a). For every individual captured for the live animal trade, collateral damage results in many more apes being killed (see Chapter 4).

As noted above, a dearth of data makes it difficult to arrive at accurate estimates of the number of apes killed for their meat; taken together, however, reports that track and document annual offtake figures provide an indication of the scale of the problem, albeit a conservative one. One study shows that, on average, more than 3,000 great apes-2,021 chimpanzees, 150 bonobos, 420 gorillas and 528 orangutans-were removed from their habitat every year during the period 2005-11. These figures are based on records of confiscated live apes, meat and parts; the estimated number of additional individuals lost per confiscated ape (1-10, depending on the species); and the estimated number of additional individuals presumed dead, based on the assumption that only $50 \%$ of all contraband is seized (Stiles et al., 2013). Another study suggests that the rates of chimpanzee and gorilla extraction are more severe. Using more direct evidence collected in 2002-03, it estimates that more than 2,000 chimpanzee and more than 600 gorilla are hunted and their carcasses traded annually in 89 urban and rural markets in a $35,000-\mathrm{km}^{2}$ area between the Cross River in Nigeria and the Sanaga River in Cameroon (Fa et al., 2006). If these numbers are typical throughout the range of both species, they indicate that the remaining populations in western Equatorial Africa-an estimated 128,700 chimpanzees and 361,900 gorillas-stand to be decimated by the wild meat trade (Strindberg et al., 2018).

\section{Barriers and Potential Solutions}

Four main barriers thwart the transition from destructive to sustainable use of wild meat (Wilkie et al., 2016). First, wild meat use is a characteristic "tragedy of the commons" problem: individuals act in their own selfinterest rather than that of the community's common good, let alone that of present and future humanity. The problem is typically worse wherever communities have no legal rights, governance is inefficient and policing is weak. Neither individuals nor communities are motivated to conserve wildlife; only when people perceive a tangible stake in "their" local biodiversity do they feel that poaching is tantamount to stealing from themselves (Wilkie et al., 2016).

Second, among species that are hunted for wild meat, great apes and other largebodied species are extirpated first, while smaller-sized ones tend to be less severely impacted (see Gallego-Zamorano et al., 2020). As predicted by the optimal foraging theory, even very rare large-bodied species become preferred targets when the opportunity arises, as they bring a high return in meat (Levi et al., 2011; Wilkie et al., 2016). The inevitable result is local extinction (Maisels et al., 2001).

Third, given the exponential rate of human population growth, wildlife production cannot expand to meet the growing demand for meat, particularly in view of increasing wealth and the concomitant surge in meat consumption (Delgado, 2003; Marques et al., 2019).

Fourth, wildlife habitat is lost through land use change for agriculture and land encroachment for infrastructure development and industry. This dynamic has an impact on food security, particularly among rural households in the tropics, as noted above. The pattern is complex and reliable 
Photo: Neither individuals nor communities are motivated to conserve wildlife; only when people perceive a tangible stake in "their" local biodiversity do they feel that poaching is tantamount to stealing from themselves. Information board in small tourist village, Bukit Lawang, Indonesia. (C) Jabruson (www.jabruson. photoshelter.com) data are only available for some habitat types, complicating the review of progress towards Aichi Biodiversity Target 5 , which envisions a minimum decrease of $50 \%$ in the rate of habitat loss for the period 2011-20 (CBD, n.d.). While Africa continues to lose hundreds of thousands of hectares of rainforest per year, the rate of deforestation in 200010 was $37-67 \%$ lower than it was during the previous decade (Mayaux et al., 2013). The Food and Agriculture Organization estimates that Africa lost $10 \%$ of its forest cover between 1990 and 2010 (FAO, 2013).

\section{Reducing Demand}

Conservationists, law enforcement agencies, communities and policymakers have variously sought to address hunting of apes for meat and parts, typically by aiming to reduce demand by bolstering the legal framework and law enforcement. Demand reduction strategies can address economic factors that drive the consumption of wild meat, for example through the provision of microcredits, affordable protein alternatives and tourism-related employment opportunities, or through public education campaigns that are designed to promote conservation and behavior change with regard to the consumption of wild meat (WCS Nigeria, n.d.; Wicander and Coad, 2018; see Box 3.3). In the longer term, school programs and awareness raising campaigns can help breed compassion and empathy (Pooley and O'Connor, 2000).

The carefully planned provision of alternative protein sources can help to establish

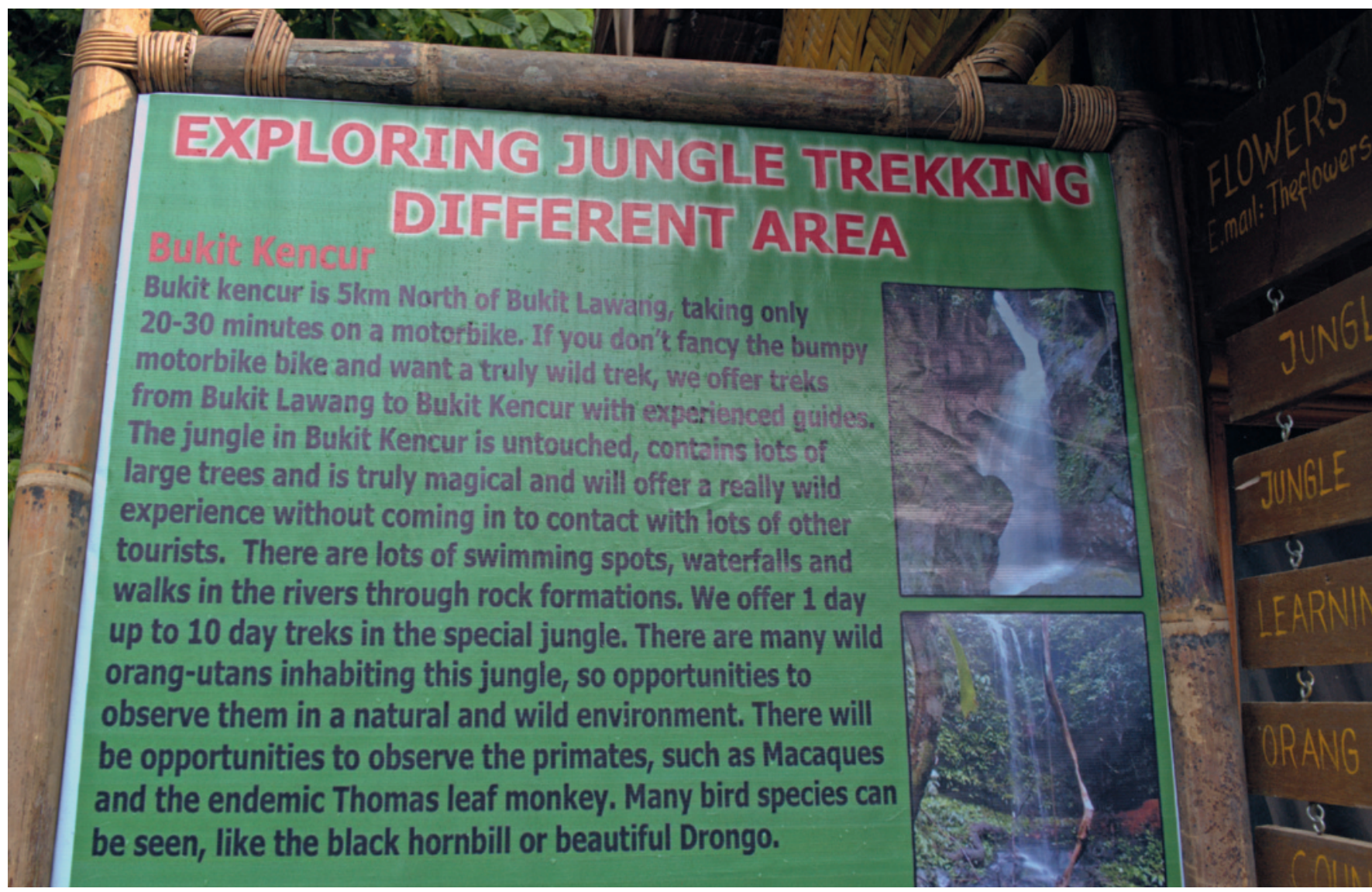


food security in rural communities and urban centers alike. Such strategies are particularly effective when they limit the use of ecologically inefficient ruminants, such as cattle, goats and sheep, in favor of more efficient sources, such as poultry and integrated aquaculture (Machovina, Feeley and Ripple, 2015). Mixed production systems that combine subsistence and cash crops with the rearing of small livestock (such as chickens or rabbits), or with the farming of fish, such as tilapia or catfish, can be a way forward (Oben, Molua and Oben, 2015). Capacity and funding shortages can undermine the implementation and effectiveness of such projects, however (Wicander and Coad, 2018).

Incentive schemes provide money or benefits to communities or individuals to encourage behavior change. Since the 1980s, efforts to incentivize local people to participate in conservation initiatives-such as integrated conservation and development projects and community-based natural resource management-have gained widespread support (see Chapter 5). Such projects can empower local people to manage wildlife sustainably while generating social and economic benefits. In a number of cases, they have successfully reduced illegal wildlife use and trade-sometimes dramatically_and incentivized strong community engagement in enforcement efforts (Roe and Booker, 2019).

Strategies for achieving community participation have focused on enhancing economic links between community members and protected areas, typically through the promotion of alternative livelihoods, including safari tourism, trophy hunting and the sale of products (Barrett and Arcese, 1995; Roe et al., 2015). The establishment of mountain gorilla tourism is an extraordinary example, as live gorillas have since become far more valuable than their meat, which has led to a reduction in hunting pressure in Uganda's Bwindi Impenetrable National Park and the DRC's Virunga National Park. Indeed, between 1981 and 2011, the population of critically endangered Virunga mountain gorillas grew by $50 \%$ (Robbins et al., 2011).

Whatever their specific goals, strategies to reduce demand for wild meat are most likely to produce the desired results if they are custom-tailored to the targeted setting, be it a rural landscape where people and wildlife live close to each other, a town that is undergoing rapid urbanization or a megacity (Wilkie et al., 2016).

In rural, economically deprived communities that are in close proximity to wildlife, people typically rely heavily on wild meat as food. Consequently, a focus on the prohibition or cessation of wild meat hunting and consumption can undermine people's food security. A more appropriate approach is one that ensures the provision of alternative protein sources or alternative livelihoods, or one that empowers communities to participate in the sustainable management of wildlife resources by devolving rights and authority over wildlife from government bodies to local communities. The successful devolution strategies used in community conservancies in Namibia could act as models for Central Africa, but their implementation in the region would require long-term investment in capacity building (Naidoo et al., 2016). In the context of devolution strategies, the best way to avoid increasing the risk to large-bodied species through indiscriminate hunting is to establish hunting regulations that are enforced by the communities themselves.

There is limited information about how best to distribute compensation to support conservation initiatives in landscapes where people and wildlife co-occur outside protected areas (Karanth et al., 2012). Given the need to safeguard the food security and livelihoods of communities that live near 
wildlife-especially inside protected areas - conservationists inevitably struggle to encourage sustainable consumption of wild meat while also protecting vulnerable wildlife (Brashares et al., 2004; Kronen et al., 2010; Mavah et al., 2018). The effects of climate change are set to cause an increase in the number of demand reduction interventions designed to conserve wildlife and habitats (Kupika and Nhamo, 2016). A global issue of this scale and complexity calls for the involvement of the international community and a robust political process.

Rapidly growing towns-especially those affiliated with logging or mining activities or experiencing political unrest or warrepresent a particular risk to regional wildlife. They tend to be market-isolated and wholly dependent on wild meat from the region, which can open up hundreds of square kilometers to wild meat hunting (Wilkie et al., 2016). In such towns, the provision of alternative protein sources via livestock farming becomes particularly important. These urban centers can encourage both locally emerging mixed production systems and market opportunities for the rural population.

People in cities and megacities consume wildlife because of affordability, cultural connections and perceived health advantages, or as luxury and status items. Although wild meat accounts for only a small proportion of the meat that is consumed overall, the numbers add up, as noted above. In urban centers, awareness campaigns that target the affluent-and often highly educateddrivers of the luxury market can facilitate behavior change. Regulations and the enforcement of laws are critical to tackling the illegal but tolerated wild meat market in these locations (Wilkie et al., 2016; see Chapter 6).

Despite a range of initiatives and considerable donor investment, however, it has proven difficult to provide local communi- ties with tangible benefits from conservation, especially in sub-Saharan Africa. The assumption that market forces will protect the environment might not apply in reality because most protected areas do not create sufficient revenue to offset the costs that communities pay to maintain them (Dressler et al., 2010; Emerton, 1998; Newmark and Hough, 2000).

The arguments deployed in favor of incentives as a means of reducing illegal wildlife hunting are apparent in claims that tourism can reduce poverty, provide economic benefits to individuals and communities, and encourage people to change their behavior towards wildlife (Cooney et al., 2018). Yet, even mountain gorilla tourism, which has been exceptionally successful in terms of stopping population decline and recovering population density, is plagued by severe economic and institutional shortcomings. Such inadequacies are typically linked to a lack of real local participation; an insignificant scale of economic returns to local people relative to costs; insufficiently resourced and trained institutions in charge of planning, managing and evaluation efforts; and an institutional complexity that constrains most activities (Tumusiime and Vedeld, 2012). That said, tourism revenue sharing has the capacity to act as a key instrument for maintaining protected areas, so long as these issues are consistently addressed.

Interventions occasionally fail or lead to unexpected results. One such example involved an experiment in social marketing, which is defined as a process that seeks to develop and integrate marketing concepts with other approaches to promote behavior that benefits individuals, communities and the greater social good. In this case, one group of local residents in Brazil received an economic incentive to consume less wild meat, namely discount coupons for chickens. The result was an increase 
BOX 3.3

\section{Using a Radio Serial Drama to Change Local Behavior Regarding Cross River Gorillas in Nigeria}

The critically endangered Cross River gorilla (Gorilla gorilla diehli) comprises at most 300 individuals. The rare subspecies is endemic to a small region on the border of Cameroon and Nigeria, which has one of the highest human population densities in Africa (see Figure 3.4; Bergl et al., 2016; Oates,
Bergl and Linder, 2004). The Cross River gorillas live in small, isolated populations that are very vulnerable to poaching, as their habitat is surrounded by human settlements and is being lost to agriculture and grazing.

In an effort to inspire positive change in attitudes and behavior towards Cross River gorillas, the education program of Wildlife Conservation Society (WCS) Nigeria launched the radio program My Gorilla-My Community (MGMC) in 2015, in collaboration with PCI Media Impact. The program features a particularly influential drama series set in a fictional area reminiscent of the geographical range of the Cross River

\section{FIGURE 3.4}

\section{Cross River State, Nigeria}

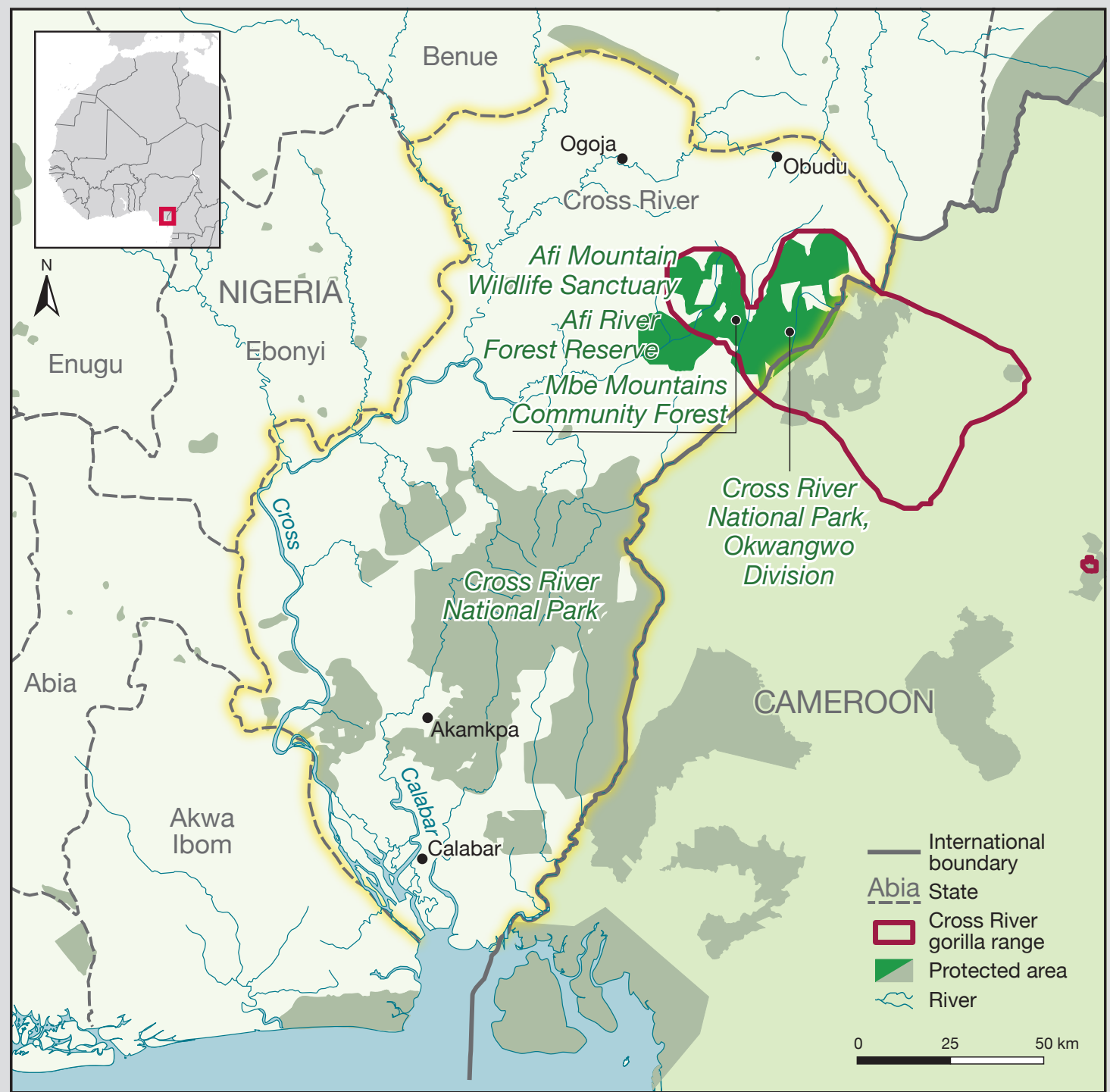

Source: UNEP-WCMC (2019b, 2019f), and Figure AO1 
gorilla and neighboring human communities. By touching the heartstrings of more than 100,000 listeners in and around the Cross River gorilla's landscape-and more than 1 million in Cross River state-it was hoped that the drama would be effective in encouraging behavior change that would help protect the gorillas (Imong and Chukwu, 2019; WCS Nigeria, n.d.).

Over time, listeners form emotional ties with the fictional characters, whose thinking and behavior regarding various environmental and conservation issues positively and gradually evolve. Through this connection, the drama can have a greater influence on listeners' values and behavior than the purely cognitive information provided via documentaries or through education. The program seeks to encourage listeners to engage in protective behavior, such as: refraining from hunting protected species, hunting in areas that are properly zoned, hunting using only legal methods, supporting law enforcement authorities and protected area staff, adopting sustainable farming methods, volunteering as a gorilla guardian, using social gatherings to encourage dialog on conservation, designing social gatherings around conservation themes, and involving a broader spectrum of community members and stakeholders in decisions about the forest that affect the entire community. The drama is broadcast in parallel with community action campaigns that support the key messages through events, written materials, speaker series, school visits and other local activities (Imong and Chukwu, 2019; WCS Nigeria, n.d.).

Results of a monitoring and evaluation survey conducted in 2019 (baseline survey conducted in 2014) show that the program is successfully changing attitudes and behaviors. There was a significant increase $(200 \%)$ in the number of respondents who support the protection of gorillas from hunting and habitat destruction; alongside a similar increase in the number of people who have adopted improved farming methods (190\%). Additionally, more people are talking to other community members to discourage gorilla hunting and/or encourage them to take up sustainable farming methods $(43 \%){ }^{2}$

in chicken consumption, yet without the expected decrease in wild meat consumption. In contrast, social marketing proved particularly successful among people of the same area who participated in community engagement activities but who were not offered an economic incentive: wild meat consumption dropped by $62 \%$ in this group (Chaves et al., 2018).

Other studies indicate that, in practice, the provision of "alternative" livelihoods is sometimes more akin to the introduction of additional sources of income, particularly if projects fail to implement conditionalities or sanctions. In such cases, the financial security of a household may increase, but illegal wildlife hunting may continue, meaning that set goals were not attained. Moreover, alternative livelihoods projects, which tend to be run by local and national non-governmental organizations, are often financially constrained and inadequately monitored; as a result, they often have variable or even poor impacts (Wicander and Coad, 2018).

\section{Enhancing the Legal Framework and Law Enforcement}

A review of national laws, regulations and penalties related to killing and trafficking in apes can serve as a first step in strengthening a country's legislative framework (see Chapter 6). That process can usefully introduce or update permits and reporting systems under the Convention on International Trade in Endangered Species of Wild Fauna and Flora (CITES), as these aim to minimize forgery and falsification (Stiles et al., 2013). Even where adequate wildlife legislation is in place, however, effective law enforcement is essential to addressing the wild meat trade (Holmern, Muya and Røskaft, 2007). In the absence of broader law enforcement, some laws have to be combined with targeted interventions to yield the desired effects, since laws that protect certain species of large mammal, for instance, may not actually change the choices made by commercial hunters (Rowcliffe, Merode and Cowlishaw, 2004).

When properly resourced, backed by political will and tailored to local circumstances, law enforcement can help to protect endangered species while simultaneously averting behavioral or political backlash by hunters, traffickers and local consumers (Wilkie et al., 2016). In addition, it can help to reduce the illegal trade in ape meat and parts, while also safeguarding apes and 
their habitats, both inside and outside of protected areas. Further, the successful prosecution of individuals who violate hunting bans, anti-trafficking laws and related legislation-be they high risk-takers such as hunters, or high-level officials who abuse their positions for private gain-is key to deterring wildlife crime along the supply chain (see Chapters 5 and 6).

At the international level, actors involved in the fight against wildlife crime would benefit from reviewing lessons learned from the struggles against the narcotics trade and corruption, as multiple parallels apply (Sosnowski, 2019; van Uhm, 2018a, 2018b; van Uhm and Moreto, 2017).

\section{Conclusion}

There is mounting evidence that apes are becoming a more desired and thus more trafficked commodity (Stiles et al., 2013). The potentially lucrative trade in their meat and parts represents an existential risk to these endangered species, partly because of their large body size and low reproductive rates, and partly because of the growing demand for their meat and parts. Unsustainable harvesting of apes is causing population decline, loss of genetic and cultural diversity, and, consequently, a deterioration of local and global ecosystem services and natural systems. For hundreds of millions of people in rural, tropical settings, these dynamics threaten food security and cultural identity.

The clandestine nature of the trade in ape meat and parts precludes an accurate assessment of the rate at which individuals are extracted from the wild. What is understood is that motivations for subsistence and commercial hunting vary, that rural communities tend to rely on wild meat as a source of protein and income, and that wealthier urban dwellers consume wild meat as a luxury item, even when cheaper protein sources are available. Moreover, weak governance and corruption encourage ape hunting.

Tackling the trade in ape meat and parts requires a combination of strategies, including ones designed to reduce consumer demand by providing and promoting alternative protein sources; raise awareness of the ecological consequences of unsustainable harvesting; enhance legal frameworks and law enforcement; and provide economic incentives to stop hunting and consumption of wild meat.

\section{Acknowledgments}

Principal authors: Julia E. Fa, ${ }^{3}$ Stephan M. Funk ${ }^{4}$ and Nikki Tagg 5

Contributors: Hillary Chukwu, ${ }^{6}$ Loretta Cheung, ${ }^{7}$ Andrew Dunn, ${ }^{8}$ Imong Inaoyom, ${ }^{9}$ Karmele Llano Sánchez, ${ }^{10}$ Sean Southey ${ }^{11}$

Box 3.3: Hillary Chukwu, Loretta Cheung, Andrew Dunn, Imong Inaoyom, Sean Southey

\section{Endnotes}

1 Hunting levels were categorized based on local interviews, the density of households in the study areas and the number of gunshots or other hunting evidence encountered during survey periods (Peres and Palacios, 2007).

2 Survey results presented in a WCS internal report seen by the authors.

3 Manchester Metropolitan University (www.mmu.ac.uk/natural-sciences/).

4 Nature Heritage (www.natureheritage.org).

5 Born Free Foundation (www.bornfree.org.uk).

6 Wildlife Conservation Society (WCS) Nigeria (www.wcs.org).

7 PCI Media (www.pcimedia.org).

8 WCS Nigeria (www.wcs.org).

9 WCS Nigeria (www.wcs.org).

10 International Animal Rescue (IAR) (www.internationalanimalrescue.org).

11 PCI Media (www.pcimedia.org). 